\title{
EDUCAÇÃO NUTRICIONAL EM GRUPO DE MULHERES RESIDENTES DE UM BAIRRO DE CRICIÚMA
}

Louyse Sulzbach Damázio Acadêmica do Curso de Nutrição, Universidade do Extremo Sul Catarinense, louyse3@hotmail.com

Débora Daleffe

Acadêmica do Curso de Nutrição, Universidade do Extremo Sul Catarinense, debora.daleffe@hotmail.com Karla Macarini

Acadêmica do Curso de Nutrição, Universidade do Extremo Sul Catarinense, karlamacarini_@hotmail.com Pâmela Colonetti Arns

Acadêmica do Curso de Nutrição, Universidade do Extremo Sul Catarinense, pamela_arns@hotmail.com Paula de Freitas Rodrigues Acadêmica do Curso de Nutrição, Universidade do Extremo Sul Catarinense, $p$ aulinha_fr20@hotmail.com Paula Rozane Vieira Guimarães Acadêmica do Curso de Nutrição, Universidade do Extremo Sul Catarinense, paulag@unesc.net

\section{RESUMO}

A globalização vem afetando diversas áreas, inclusive a alimentação da população mundial. A mudança no ritmo de vida, a entrada da mulher no mer- 
cado de trabalho e a urbanização refletiram diretamente na forma com que o ser humano vem se alimentando (LELIS; TEIXEIRA; SILVA, 2012). Ao considerar a importância da alimentação saudável no grupo feminino, o objetivo desta ação educativa foi de propagar informação e bons hábitos alimentares para um público de mulheres adultas. Foi realizada uma ação educativa com oito mulheres, com idades entre 24 e 68 anos, de um bairro de Criciúma (SC). As mulheres foram convidadas para um "café colonial saudável”, no qual cada participante deveria elaborar um prato que considerasse saudável para contribuir com a mesa do café. Na roda de conversa, foram abordados alguns temas, como a importância das vitaminas, fibras e água na alimentação saudável, dicas de técnica dietética, rotulagem nutricional e alimentos light e diet, além da apresentação do guia de bolso "Para uma Alimentação Saudável” e "Os Dez Passos para uma Alimentação Saudável”, do Ministério da Saúde. Em um segundo momento, cada uma das participantes foi convidada a dar uma breve explicação sobre o prato que havia levado ao encontro, explicando o porquê de considerá-lo saudável. Durante as explicaçôes, as convidadas fizeram perguntas, sanaram dúvidas e contribuíram com o conhecimento, por meio de experiências vividas por elas, sobre os diversos temas abordados. De uma forma geral, as participantes demonstraram um conhecimento considerável sobre alimentação saudável. Observou-se uma grande dificuldade em colocar em prática os hábitos saudáveis e fazer o uso dos alimentos saudáveis, pois a maioria alegava falta de tempo, devido às suas rotinas diárias, e preço dos alimentos. As preparaçóes levadas foram bolo de laranja, panqueca integral de frango, brownie integral sem lactose, espetinho de frutas, mix de fibras, sanduíche natural de pão integral, etc.

Palavras-chave: Mulheres; Hábitos Alimentares; Educação Nutricional.

\section{AGRADECIMENTOS}

Agradecemos a todas as mulheres que participaram da ação educativa, principalmente pela disponibilidade e atenção. Também agradecemos à professora Paula, que nos auxiliou desde o princípio e continua até hoje. 


\section{REFERÊNCIAS}

LELIS, C. T.; TEIXEIRA, K. M. D.; SILVA, N. M. A inserção feminina no mercado de trabalho e suas implicaçóes para os hábitos alimentares da mulher e de sua família. Saúde Debate [on-line], v.36, n.95, p.523-532, 2012. 